\title{
Carbamazepine intoxication in alcohol dependent epileptic patients
}

\author{
Wojciech Piekoszewski ${ }^{1}$, Ewa Florek ${ }^{2}$, Dorota Szpak ${ }^{3}$, Lucyna Kramer ${ }^{4}$, \\ Wojciech Jawień ${ }^{5}$ \\ ${ }^{1}$ Department of Analytical Chemistry, Jagiellonian University, Ingardena 3, PL 30-060 Kraków, Poland \\ ${ }^{2}$ Laboratory of Environmental Research, Department of Toxicology, University of Medical Sciences, Dojazd 30, \\ PL 60-631 Poznań, Poland \\ ${ }^{3}$ Toxicology Clinic, Jagiellonian University, Złotej Jesieni 1, PL 31-826 Kraków, Poland \\ ${ }^{4}$ Department of Computer Sciences, University of Medical Sciences, Dąbrowskiego 79, PL 60-529 Poznań, Poland \\ ${ }^{5}$ Department of Pharmacokinetics and Physical Pharmacy, Jagiellonian University, Medyczna 9 , \\ PL 30-688 Kraków, Poland \\ Correspondence: Wojciech Piekoszewski, e-mail: wpiekosz@tlen.pl
}

\begin{abstract}
:
Carbamazepine is frequently administrated to alcohol addict patients. The aim of this study was to evaluate the influence of alcohol addiction on carbamazepine pharmacokinetics and severity of drug intoxication. The total of 158 carbamazepine intoxicated patients participated in the study (76 non-alcohol-dependent, and 82 alcohol-dependent subjects). The results of the study indicate that the level of unconsciousness depends on carbamazepine concentration. The frequency of anticholinergic toxidrome was higher in alcohol-dependent patients (88.6\% - alcohol-abused subjects, and 78.3\% - alcoholics in abstinency) comparing to non-alcoholdependent epileptics (67.1\%). The average biological half-life of carbamazepine in non-addicted epileptics was $41.5 \mathrm{~h}, 43.5 \mathrm{~h}$ for alcohol-dependent patients during abstinency, and 38.6 in abused patients. It may be concluded that ethanol doesn't influence the pharmacokinetic and pharmacodynamic of carbamazepine in acute drug intoxication.
\end{abstract}

Key words:

carbamazepine, alcohol abuse, interaction

\section{Introduction}

Carbamazepine, apart from many therapeutic applications, especially to control generalized tonic-clonic seizures and partial seizures in children and adults, is broadly applied in the detoxification therapy for alcohol-dependent patients and in the treatment of withdrawal syndrome $[15,23]$, and it is an alternative to benzodiazepines [2]. Its application in the withdrawal syndrome is related to the anti-convulsant, anxiety-relieving, sedative, and mood-stabilizing action [9].

Although on the basis of the experiences gained so far, the intoxication resulting from the overdose of carbamazepine alone rarely constitutes a life threat, 
however, it is a problem due to the frequency of the phenomenon. The mixed intoxications with carbamazepine and ethanol are particularly dangerous from the toxicological point of view.

During intoxication, the absorption of carbamazepine from the gastrointestinal tract is slowed down even up to $72 \mathrm{~h}$, which may be a consequence of its poor water solubility and a weaker bowel movement related to its anticholinergic action [3].

As a result of carbamazepine biotransformation, more than 30 metabolites are produced, including 10,11-epoxide, an active metabolite [10]. For clinical purpose, carbamazepine can be measured in saliva and genotype has no effect on its secretion to saliva [6].

The simultaneous administration of carbamazepine with other drugs or after the consumption of alcohol may lead to interactions which may have dangerous effects. This problem is particularly important among alcohol-dependent patients. Because the medical use of carbamazepine among the alcohol addicted is very frequent, a great risk of occurrence of such interactions exist.

The aim of this paper was to evaluate the impact of alcohol acute intoxication and alcohol abuse on the course of carbamazepine intoxication in patients with epilepsy.

\section{Materials and Methods}

The total of 158 patients treated at the Toxicology Clinic of the Jagiellonian University in Kraków, Poland participated in the study. All patients were divided into three groups. Group I - patients intoxicated with carbamazepine and non-alcohol-dependent, groups II and III included alcohol-dependent patients, who overdosed carbamazepine. Patients from group II were abstinent and in group III alcohol was detected in blood at the admission to the clinic (Tab. 1). The cause of carbamazepine overdosing (accidental or attendants to commit suicide) were not established.

All medical procedures in this study were carried out in concordance with ethical standards and the Helsinki Declaration (1975 with revision of 2000).

\section{Patients and procedures}

At the admission to the hospital, a standardized medical history and general physical examination were
Tab. 1. Demographic data of studied patients

\begin{tabular}{c|cc|cc|cc}
\hline Parameter & \multicolumn{2}{c}{ Group I } & \multicolumn{2}{c}{ Group II } & \multicolumn{2}{c}{ Group III } \\
\hline $\begin{array}{c}\text { Number } \\
\text { of patients }\end{array}$ & \multicolumn{2}{c}{76} & \multicolumn{2}{c}{35} & \multicolumn{2}{c}{47} \\
\hline Sex & Male & Female & Male & Female & Male & Female \\
& 28 & 48 & 32 & 3 & 38 & 9 \\
\hline $\begin{array}{c}\text { Age [year] } \\
\text { (mean } \pm \text { SD) }\end{array}$ & $27.3 \pm 13.4$ & $42.9 \pm 8.9$ & $38.7 \pm 9.3$ \\
\hline
\end{tabular}

Group I - non-alcohol-dependent epileptics with carbamazepine intoxication. Group II - alcohol-dependent epileptics with carbamazepine intoxication (abstinent at the admission to the hospital). Group III - alcohol-dependent epileptics with carbamazepine intoxication (abused at the admission to the hospital)

performed and additionally a standard resting electrocardiogram was recorded. The level of consciousness disturbances was assessed on the basis of the Matthew-Lawson Coma Scale.

After regaining the consciousness, the psychological examination with the application of the SelfAdministered Alcohol Screening Test (SAAST) [19] was carried out in all patients.

At the moment of admission to the hospital, a blood sample was collected in order to estimate the activity of selected enzymes and concentrations of sodium (Synchrone CX7 analyzer, Beckman Co.), ethanol and carbamazepine (AxSYME, Abbott Co.). The collected samples of urine were used to perform a standard toxicological analysis for various drugs in urine (amphetamine derivatives, cannabinols, benzodiazepines, barbiturates and phenytoin), and determination of carbamazepine in serum and ethanol in whole blood was performed. Carbamazepine was additionally determined in serum samples collected 2-6 times during hospitalization.

All patients with known enzyme inducers, (e.g. barbiturates, phenytoin), and drugs impacting their clinical condition (e.g., benzodiazepies) detected in urine were excluded from the study.

\section{Statistical and pharmacokinetic calculations}

The results were assessed by the variance analysis method. Correlations between the respective variables were indicated on the basis of Spearman coefficient. The pharmacokinetic calculations were carried out by the statistical moment's analysis. 


\section{Results}

The age of the patients in group I was lower compared with patients in two other groups. The gender structure was statistically different (Tab. 1).

\section{General medical examination}

The arterial systolic and diastolic blood pressure (Tab. 2 ) was statistically significantly lower in the group of non-alcohol-dependent subjects than in both groups of alcohol-dependent patients.

The heart rate was higher in the group of alcoholdependent patients regardless of the presence of alcohol in blood tests in comparison with the group of non-addicts (Tab. 2). The concentration of carbamazepine had no impact on the heart rate.

In the electrocardiograms of the subjects who were not alcohol-dependent, no abnormalities were found except for the disturbances in the intraventricular

Tab. 2. Results of medical examination and biochemical tests

\begin{tabular}{|c|c|c|c|c|}
\hline \multicolumn{2}{|l|}{ Parameter } & Group I & Group II & Group III \\
\hline \multicolumn{2}{|l|}{$\begin{array}{l}\text { Systolic blood } \\
\text { pressure [mmHg] }\end{array}$} & $\begin{array}{l}125.8 \\
\pm 20.7\end{array}$ & $\begin{array}{l}142 \\
\pm 20.5^{*}\end{array}$ & $\begin{array}{l}140 \\
\pm 20.6^{*}\end{array}$ \\
\hline \multicolumn{2}{|l|}{$\begin{array}{l}\text { Diastolic blood } \\
\text { pressure [mmHg] }\end{array}$} & $\begin{array}{l}80.8 \\
\pm 14.7\end{array}$ & $\begin{array}{l}89.8 \\
\pm 12.8^{*}\end{array}$ & $\begin{array}{l}87.5 \\
\pm 16.1^{*}\end{array}$ \\
\hline \multicolumn{2}{|l|}{$\begin{array}{l}\text { Heart rate } \\
\text { [beats/min] }\end{array}$} & $\begin{array}{l}91 \\
\pm 17\end{array}$ & $\begin{array}{l}98 \\
\pm 18^{*}\end{array}$ & $\begin{array}{l}100 \\
\pm 16^{\star}\end{array}$ \\
\hline \multicolumn{2}{|c|}{ Cholinolytic syndrome [\%] } & 67.1 & $78.4^{*}$ & $88.5^{\star}$ \\
\hline \multicolumn{2}{|c|}{ Physostigmine application [\%] } & 19.7 & 21.7 & $27.0^{\star}$ \\
\hline \multicolumn{2}{|l|}{ AIAT activity [U/] } & $\begin{array}{l}25.2 \\
\pm 23.4\end{array}$ & $\begin{array}{l}32.2 \\
\pm 29.0\end{array}$ & $\begin{array}{l}31.0 \\
\pm 30.6\end{array}$ \\
\hline \multicolumn{2}{|l|}{ AspAT activity [U/] } & $\begin{array}{l}35.9 \\
\pm 54.9\end{array}$ & $\begin{array}{l}56.6 \\
\pm 86.9^{*}\end{array}$ & $\begin{array}{l}47.33 \\
\pm 75.9^{*}\end{array}$ \\
\hline \multirow{5}{*}{$\begin{array}{l}\text { Degree of coma } \\
\text { during admission to } \\
\text { the hospital [\%] }\end{array}$} & 0 & 22.06 & 11.43 & 23.92 \\
\hline & 1 & 23.38 & 48.57 & 15.21 \\
\hline & $\|$ & 35.07 & 22.86 & 39.13 \\
\hline & III & 14.29 & 17.14 & 19.57 \\
\hline & IV & 5.20 & 0 & 2.17 \\
\hline
\end{tabular}

Group | - non-alcohol-dependent epileptics with carbamazepine intoxication. Group || - alcohol-dependent epileptics with carbamazepine intoxication (abstinent at the admission to the hospital). Group III - alcohol-dependent epileptics with carbamazepine intoxication (abused at the admission to the hospital). Data are the mean $\pm \mathrm{SD}$, number of patients is presented in Table 1. * Differences statistically significant from group |; $p<0.05$ conductivity in three patients ( $\mathrm{rSr}$ in $\mathrm{V} 1)$. The sinus rate acceleration was observed in $18 \%$ of the studied group. In one case, supraventricular tachycardia was recorded. Among alcohol addicts, a block of the left bundle branch was observed, and among three of them - rSr' in V1 was recorded. The non-specific abnormalities of ST-T were present in six patients. In one case, the sinusal bradycardia 55/min occurred. The supraventricular tachycardia was recorded in two patients. The sinus rate acceleration was present in almost $30 \%$ of the studied group.

\section{Laboratory tests}

The mean value of activity of AlAT in all studied groups was below upper limit of reference value (40 U/l). On the other hand, the activity of AspAT was higher than reference value $(40 \mathrm{U} / \mathrm{l})$ in both groups of addicted patients and statistically higher comparing with non-alcohol-dependent patients (Tab. 2). The mean values of concentration of sodium in plasma were in the normal range (135-145 $\mathrm{mM} / \mathrm{l})$ and did not differ between studied groups (data not shown).

Tab. 3. Results of the toxicological and pharmacokinetic examination of carbamazepine

\begin{tabular}{|c|c|c|c|}
\hline Parameter & Group I & Group II & Group III \\
\hline $\begin{array}{l}\text { Estimated dose } \\
\text { of carbamazepine [g] }\end{array}$ & $\begin{array}{l}8.3 \\
\pm 5.1\end{array}$ & $\begin{array}{l}9.6 \\
\pm 6.7\end{array}$ & $\begin{array}{l}9.5 \\
\pm 6.6\end{array}$ \\
\hline $\begin{array}{l}\text { Time from drug } \\
\text { taking }[\mathrm{h}]\end{array}$ & $\begin{array}{l}6.5 \\
\pm 6.3\end{array}$ & $\begin{array}{l}7.2 \\
\pm 4.8\end{array}$ & $\begin{array}{l}6.0 \\
\pm 4.2\end{array}$ \\
\hline $\begin{array}{l}\text { Time of } \\
\text { hospitalization [day] }\end{array}$ & $\begin{array}{l}6.8 \\
\pm 6.3\end{array}$ & $\begin{array}{l}5.8 \\
\pm 3.8\end{array}$ & $\begin{array}{l}7.5 \\
\pm 5.3\end{array}$ \\
\hline $\begin{array}{l}\text { Maximum carbamazepine } \\
\text { concentration }[\mathrm{mg} /]\end{array}$ & $\begin{array}{l}30.2 \\
\pm 10.9\end{array}$ & $\begin{array}{l}34.7 \\
\pm 11.8\end{array}$ & $\begin{array}{l}29.5 \\
\pm 12.4\end{array}$ \\
\hline Biological half-live [h] & 41.5 & 43.4 & 38.6 \\
\hline Clearance $[\mathrm{l} / \mathrm{h} / \mathrm{kg}]$ & $\begin{array}{l}0.067 \\
\pm 0.005\end{array}$ & $\begin{array}{l}0.0701 \\
\pm 0.006\end{array}$ & $\begin{array}{l}0.0693 \\
\pm 0.004\end{array}$ \\
\hline $\begin{array}{l}\text { Volume of } \\
\text { distribution [l/kg] }\end{array}$ & 3.71 & 3.86 & 3.89 \\
\hline
\end{tabular}

Group I - non-alcohol-dependent epileptics with carbamazepine intoxication. Group || - alcohol-dependent epileptics with carbamazepine intoxication (abstinent at the admission to the hospital). Group III - alcohol-dependent epileptics with carbamazepine intoxication (abused at the admission to the hospital). Data are the mean $\pm \mathrm{SD}$, number of patients is presented in Table 1 


\section{Toxicological tests}

The mean doses of carbamazepine used by patients, established on the basis of a medical interview, were similar in all study groups (Tab. 3).

The largest group was formed by patients who took an intoxicating dose below 10 grams of carbamazepine ( $81.82 \%$ in group I; $68,57 \%$ in group II and $73,91 \%$ in group III). Also, the time that expired from the moment of drug administration to the moment of admission to the hospital did not differ between the studied groups (Tab. 3).

The toxicological tests demonstrated that the mean of maximum concentration of carbamazepine in studied groups ranged from 29.5 to $34.7 \mathrm{mg} / \mathrm{l}$. Despite the highest concentration of carbamazepine in the group of abused patients, the differences in drug concentration in comparison to the remaining groups were not statistically significant.

The statistical analysis indicates that there is a relationship between the maximal carbamazepine concentration and the dose of the drug taken by the patient.

Within the group of patients admitted to the hospital and intoxicated with alcohol, the concentrations of alcohol ranged from 0.5 to $3.0 \mathrm{~g} / \mathrm{l}$, but in almost $50 \%$ of cases, the concentration of ethanol ranged from 1.1 to $2.0 \mathrm{~g} / \mathrm{l}$, and the mean concentration of alcohol was $1.4 \pm 0.8 \mathrm{~g} / 1$.

It was not demonstrated that the differences in duration of hospitalization within the respective groups were statistically significant (Tab. 3), however, the time of hospitalization depended on concentration of carbamazepine, and when the concentration was higher than $30 \mathrm{mg} / \mathrm{l}$, the time of hospitalization was longer than 7 days.

A parameter proving the severity of intoxication evaluated in the conducted tests was the degree of coma. The distribution of the degrees of coma in the studied groups in the first day of hospitalization is presented in Table 2 .

During the subsequent days, the degree of coma in the studied subiects was lowered and in the second day the number of patients with the consciousness disturbance lowered to 105 persons. On the fifth day, the number of patients with consciousness disturbance decreased to about $5 \%$.

The degree of consciousness disturbance at the first day of hospitalization correlated with the concentration of carbamazepine in blood and the Spearman's coefficients of correlation for the first, second and

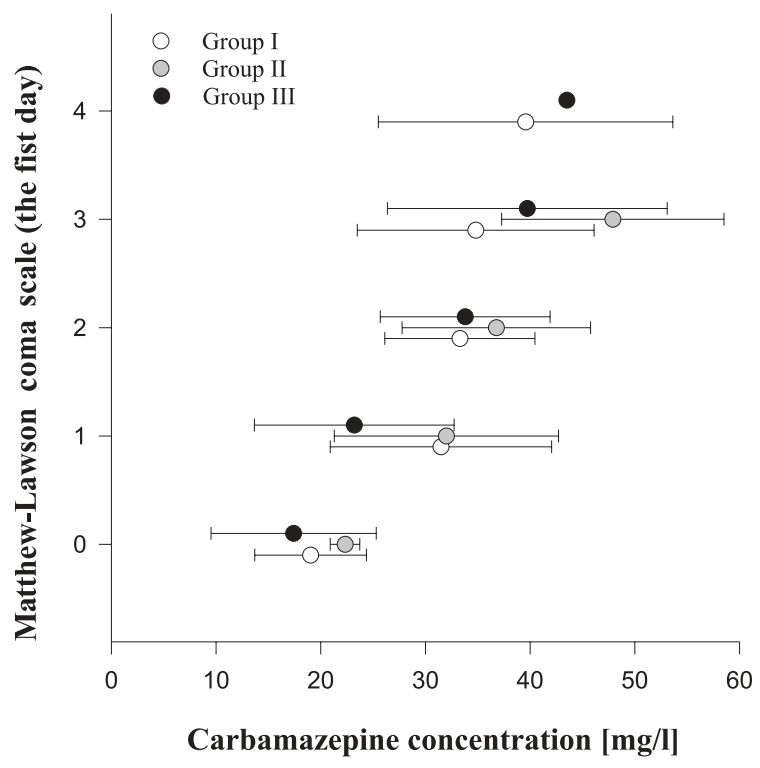

Fig. 1. Relationship between carbamazepine concentration and score in Matthew-Lawson coma scale. Group I - epileptics nonalcohol dependent with carbamazepine intoxication. Group \| alcohol-dependent epileptics intoxicated with carbamazepine (abstinent at the admission to the hospital). Group ||I - alcoholdependent epileptics with carbamazepine intoxication (abused at the admission to the hospital). Data presented are the mean $\pm S D$, number of patients is presented in Table 1

third studied groups were $0.5399,0.5817$ and 0.6982 , respectively, and were statistically significant $(\mathrm{p}<$ 0.05) (Fig. 1).

With regard to the percentage, the cholinolytic syndrome occurred most frequently within the group of alcohol-dependent persons and intoxicated with it (88.5\%). More seldom (78.4\%), this syndrome was observed in the group of addicts, in whose case, no presence of alcohol was detected, whereas in the group of non-addicts, occurred only in $67.11 \%$ (Tab. $2)$. The frequency of occurrence of the cholinolytic syndrome depended on the concentration of carbamazepine. In the case of 35 out of 158 patients, the intesity of the symptoms of cholinolytic syndrome caused the necessity of administering physostigmine salicylate (Tab. 2). The necessity for its administration did not occur more often within the group of alcohol-dependent persons comparing to the group of non-addicted patients.

The symptoms of respiratory insufficiency observed among patients were indication for intubations and mechanical ventilation in $2.3 \%$ of patients in group I, 3.5\% in group II and $1.4 \%$ in group III. The mean time of mechanical ventilation was three days in the first group, two days in the second group and as much as five days in the third group. 


\section{Pharmacokinetic analysis}

The obtained results prove that the majority of patients came to the clinic after complete absorption of the drug. Within the group of non-addicted persons, this amounted to $100 \%$, whereas in group II of alcohol addicts, who were not intoxicated with it, the absorption process was not completed in $9.21 \%$ of patients, and in group III, it was $24.44 \%$. The basic pharmacokinetic parameters are presented in Table 3 .

\section{Psychological test}

The alcohol dependence was diagnosed basing on ICD-10 criteria and additionally it was evaluated with the SAAST test. The differences between scores achieved by alcohol-dependent subjects $(21.3 \pm 4.46)$ and non-dependent persons $(2.31 \pm 2.8)$ were statistically significant.

\section{Discussion}

It is a well-known fact that carbamazepine increases its own metabolism $[8,18]$. Therefore, a long period (at least one year) of carbamazepine administration was a condition for qualifying a patient to the study group.

On the basis of the medical history, it was found that the mean time from drug administration in the groups studied was similar and ranged between 6.0-7.2 h, with the mean estimated dose of carbamazepine 8.3-9.6 g. The mean maximum concentrations of carbamazepine within the studied groups were $30.2 \pm 10.9 \mathrm{mg} / 1$ in group I, $34.7 \pm 11.8 \mathrm{mg} / \mathrm{l}$ in group II and $29.5 \pm 12.4 \mathrm{mg} / 1$ in group III. In many of cases the carbamazepine concentrations were within the toxic range $(20-40 \mathrm{mg} / \mathrm{l})$.

In this study, no impact of age on the elimination and toxicity of carbamazepine were confirmed as suggested in some papers. This can be explained by the fact that only adults participated in the study, whereas the suggested differences typically can be seen between adults, children and older persons [7].

The sinusal tachycardia occurring in carbamazepine intoxications is a frequent symptom reported in the literature, as a result of the vagolytic action of carbamazepine [16]. Evaluating the heart rate within the studied groups, it was observed that it was higher within the group of alcohol-dependent persons, and the differences were statistically significant. This may result from a direct toxic impact of alcohol on the myocardium, secondary electrolytic disorders, and the presence of cardiotoxic acetic aldehyde [14, 21].

Statistically significant differences in the values of the arterial blood pressure were also observed within the studied groups. The described impact of carbamazepine on the cardiovascular system indicates a possibility of occurrence of both hypotension and hypertension $[13,17]$. The statistical analysis demonstrated that both the systolic and diastolic pressure were significantly higher in the group of alcoholdependent persons. As noticed by Bannan et al., the systolic and diastolic arterial blood pressure is related to the seriousness of withdrawal syndrome [1].

The rhythm and conductivity disorders resulting from the cardiotoxic action of carbamazepine occur fairly seldom. Within the studied group, this type of carbamazepine action was not observed. The lack of such disorders in this study may result from the fact that high concentrations of carbamazepine in the studied patients exceeding $50 \mathrm{mg} / 1$ occurred rarely, whereas heart disorders described in the literature show high concentrations of carbamazepine exceeding these values [20].

The consciousness disturbance within the studied groups of patients during admitting to the hospital was observed in $81.1 \%$ of persons in the group of non-addicts, $88.6 \%$ of sober alcohol-dependent patients and $76.6 \%$ of drunk alcohol-dependent persons poisoned by carbamazepine. The intensity of consciousness disturbance correlated with the carbamazepine concentration in blood. The correlation between the degree of coma and the level of carbamazepine in blood confirmed the results of Feldman et al. [4].

The cases of liver damage as a result of toxic carbamazepine action are described in the literature. In the studied groups, the mean values of AlAT activity were in the range of the reference value. The activity of AspAT, was above reference value in both groups of alcohol-dependent patients, but not in non-alcohol dependend patients with carbamazepine intoxication.

Both carbamazepine and alcohol may cause symptoms of cholinolytic toxidrome [10]. However, the cholinolytic toxidrome occurred most often within the group of addicted persons, who were intoxicated with alcohol. The statistical analysis demonstrated a good 
correlation of its occurrence with the carbamazepine concentration in blood. In cases of intensified cholinolytic symptoms, the physostigmine salicylate is recommended. In spite of the undeniable relationship between the occurrence of the cholinolytic symptoms and the carbamazepine concentration in blood, the application of physostigmine salicylate was most often indicated within the group of alcohol-dependent patients with ethanol present in blood, and the differences between the groups of addicted and nonalcohol-dependent persons with regard to the drug administration were statistically significant. This fact may be explained by the presence of alcohol, which also has a cholinolytic action.

Most authors emphasize the correlation between the concentrations of carbamazepine with its toxicity. Montogomery et al. observed the symptoms of respiratory insufficiency with the carbamazepine concentrations exceeding $40 \mathrm{mg} / 1$ [11]. Among the persons subjected to the study, the necessity for intubations and mechanical ventilation was necessary in few cases. The carbamazepine concentrations observed at that time was $40-60 \mathrm{mg} / \mathrm{l}$. Within group I, $3(2.9 \%)$ patients required intubations, whereas the mechanical ventilation was implemented in 2 cases $(1.5 \%)$. Within the group of alcohol-dependent patients, intubation was required in 5 patients (4\%) of which 4 were inebriated with alcohol. The mechanical ventilation in this group was applied in 4 patients $(3.2 \%)$ of whom three were inebriated with alcohol.

In the studies of Spiller et al. [16], the indications for artificial ventilation occurred among patients with the carbamazepine concentration ranging between $20-59 \mathrm{mg} / 1$ and the time of mechanical ventilation was $12-23 \mathrm{~h}$. Within the studied group, the time was longer, and ranged from 2 days (group II) to 5 days (group III). A clearly longer period of mechanical ventilation in the group studied by us was most probably related to higher concentrations of carbamazepine in blood as they exceeded the levels given by Spiller, where the concentration higher than $50 \mathrm{mg} / \mathrm{l}$ were recorded only in one case [16].

When analyzing the duration of stay in the hospital, it was proved that it was dependent on the carbamazepine concentration in blood. The time of hospitalization in carbamazepine intoxication assessed by Spiller demonstrated that the prolonged time of hospital stay correlate with carbamazepine concentration in blood [16].
The reports concerning pharmacokinetics of carbamazepine in acute intoxications are not frequent, and the presented results are not unambiguous. In the study based on a relatively small group of intoxicated patients, Hundt showed that the elimination of carbamazepine takes place in accordance with the linear kinetics [5]. On the other hand, in other studies, it was demonstrated that the elimination of carbamazepine occurs in accordance with zero order kinetics, and the rate of elimination ranges from 0.5 to $0.8 \mathrm{mg} / \mathrm{l} / \mathrm{h}$ [22]. The results most similar to presented in this paper were obtained by Montoya-Cabrera et al. $\left(\mathrm{t}_{0.5} 18-54 \mathrm{~h}\right)$ [12].

Our study showed an increase of arterial blood pressure and heart rate in alcohol-dependent persons but it was not fairly elevated by carbamazepine intoxication. Other obtained results did not confirmed an impact of alcohol addiction and the level of intoxication on pharmacodynamics and pharmacokinetics of carbamazepine.

\section{References:}

1. Bannan LT, Potter JF, Beeverse DG, Saunders JB, Walters JR, Ingram MC: Effects of alcohol withdrawal on blood pressure, plasma renin activity, aldosterone, cortisol and dopamine beta hydroxylase. Clin Sci, 1984, 66, 659-663.

2. Bayard M, McIntyre J, Hill KR, Woodside J Jr: Alcohol withdrawal syndrome. Am Fam Physician, 2004, 69, 1443-1450.

3. Desphande G, Meert KL, Valentini, RP: Repeat charcoal hemoperfusion treatments in life threatening carbamazepine overdose. Pediatr Nephrol, 1999, 13, 775-777.

4. Feldman R, Burda PR, Glinska-Serwik M, Kotlarska M, Szajewski J: Correlation of carbamazepine level in blood with clinical, intoxication status, evaluated with the help of the APACHE II system and the Metthew coma scale. Przegl Lek, 1997, 54, 411-415.

5. Hundt HK, Aucamp AK, Muller PO: Pharmacokinetic aspects of carbamazepine and its two major metabolites in plasma during overdose. Human Toxicol, 1983, 2, 607-614.

6. Kurzawski M, Bartnicka L, Droździk A, Białecka M, Droździk M: Effect of $A B C B 1$ (MDR1) 3435C > T polymorphism on salivary secretion of carbamazepine. Pharmacol Rep, 2007, 59, Suppl 1, 275-279.

7. Lanchote VL, Bonato PS, Campos GM, Rodrigues I: Factors influencing plasma concentration of carbamazepine and carbamazepine 10,11-epoxide in epileptic children and adults. Ther Drug Metabol, 1995, 17, 47-52. 
8. Liu H, Delgedo MR: The influence of polytherapy on the relationships between serum carbamazepine and its metabolites in epileptic children. Epilepsy Res, 1994, 17, 257-269.

9. Lucht M, Kuehn KU, Armbruster J, Abraham G, Gaensicke M, Barnow S, Tretzel H, Freyberger HJ: Alcohol withdrawal treatment in intoxicated and non-intoxicated patients: a controlled open-label study with tiapride/carbamazepine, clomethazole and diazepam. Alcohol Alcoholism, 2003, 38, 168-175.

10. Maggs JL, Pirmohamed M, Kitteringham NR, Park BK: Characterisation of the metabolites of carbamazepine in patient urine by liquid chromatography/mass spectrometry. Drug Metab Dispos, 1997, 25, 275-279.

11. Montgomery VL, Richman BJ, Goldsmith LJ, Rodgers GC Jr: Severity and carbamazepine levels at time initial. Poisoning centre contact correlate with outcome in carbamazepine poisoning. Clin Toxicol, 1995, 33, 311-323.

12. Montoya-Cabrera MA, Sauceda-Garcia JM, EscalanteGalindo P, Flores-Alvarez E, Ruiz-Gómez A: Carbamazepine poisoning in adolescent suicide attempters. Effectives of multiple dose activated charcoal in enhancing carbamazepine elimination. Arch Med Res, 1996, 7, 485-489.

13. Mordel A, Sivilotti MLA, Linden CH: Fatal TCA-like cardiotoxicity following carbamazepine overdose. Clin Toxicol, 1998, 36, 472-476.

14. Opolski G, Torbicki A: Auricular fibrillation (in Polish). Urban \& Partner, Wrocław. 2000.

15. Soyka M, Morhart-Klute V, Horak M: A combination of carbamazepine/tiapride in outpatient alcohol detoxifica- tion. Results from an open clinical study. Eur Arch Psychiatry Clin Neurosci, 2002, 252, 197-200.

16. Spiller AH, Krenzelok EP, Cookinks DE: Carbamazepine overdose: prospective study of serum levels and toxicity. Clin Toxicol, 1990, 28, 445-456.

17. Spiller F, Carlisle FM: Carbamazepine and NMS. Br J Psychiatry, 2002, 158, 434-435.

18. Spina E, Pisani F, Perucca E: Clinically significant pharmacokinetic drug interaction with carbamazepine. Clin Pharmacokinet, 1996, 31, 198-214.

19. Swenson WM, Morse RM: The use of a selfadministered alcoholism screening test (SAAST) in a medical center. Mayo Clin Proc, 1975, 50, 2048.

20. Tibbals J: Acute intoxication to carbamazepine: clinical effects and serum concentrations. J Pediatr, 1992, 12, 295-299.

21. Wickramansinghe SN, Hasan R, Knapey Z: Differences in the serum levels of acetaldehyde and cytotoxic acetaldehyde albumin complexes after the consumption of red and white wine: in vitro effects of flavonoids, vitamin $\mathrm{E}$ and other dietary antioxidants on cytotoxic complexes. Alcohol Clin Exp Res, 1996, 20, 799-806.

22. Winnicka RI, Topaciński B, Szymczak WM, Szymańska B: Carbamazepine poisoning: elimination kinetics and quantitative response. Clin Toxicol, 2002, 40, 759-765.

23. Zilker T: Alcohol withdrawal syndrome and delirium tremens. Diagnosis and therapy. MMW Fortschr Med, 2004, 141, 26-30.

Received:

July 13, 2009; in revised form: October 1, 2009 